\title{
Risk factors for poor outcomes in patients with open-globe injuries
}

\author{
This article was published in the following Dove Press journal: \\ Clinical Ophthalmology \\ I August 2016 \\ Number of times this article has been viewed
}

\author{
Rita D Page' \\ Sumeet K Gupta' \\ Thomas $L$ Jenkins' \\ Zeynel A Karcioglu ${ }^{1,2}$ \\ 'Department of Ophthalmology, \\ ${ }^{2}$ Department of Pathology, University \\ of Virginia, Charlottesville, VA, USA
}

Purpose: The aim of this study was to identify the risk factors that are predictive of poor outcomes in penetrating globe trauma.

Patients and methods: This retrospective case series evaluated 103 eyes that had been surgically treated for an open-globe injury from 2007 to 2010 at the eye clinic of the University of Virginia. A total of 64 eyes with complete medical records and at least 6 months of follow-up were included in the study. Four risk factors (preoperative best-corrected visual acuity [pre-op BCVA], ocular trauma score [OTS], zone of injury [ZOI], and time lapse [TL] between injury and primary repair) and three outcomes (final BCVA, monthly rate of additional surgeries [MRAS], and enucleation) were identified for analysis.

Results: Pre-op BCVA was positively associated with MRAS, final BCVA, and enucleation. Calculated OTS was negatively associated with the outcome variables. No association was found between TL and ZOI with the outcome variables. Further, age and predictor variable-adjusted analyses showed pre-op BCVA to be independently positively associated with MRAS $(P=0.008)$ and with final BCVA $(P<0.001)$, while the calculated OTS was independently negatively associated with final BCVA $(P<0.001)$, but not uniquely associated with MRAS $(P=0.530)$.

Conclusion: Pre-op BCVA and OTS are best correlated with prognosis in open-globe injuries. However, no conventional features reliably predict the outcome of traumatized eyes.

Keywords: penetrating globe trauma, eye injuries, prognostic factors, predictors, visual outcome, ocular trauma score

\section{Introduction}

Open-globe injuries (OGIs), defined as full-thickness penetration of the eye wall, ${ }^{1}$ are devastating due to the sudden and wide-ranging nature of the trauma. ${ }^{2}$ As the leading cause of visual loss for working-aged individuals, the cost of OGIs to the patient and society is considerable, not only because of medical suffering and expenditures, but also due to lifelong loss of productivity. ${ }^{3}$ Many studies have been conducted to evaluate the factors that are associated with poor prognosis in patients with OGI. ${ }^{4-19}$ This information helps physicians to make important management decisions and counsel patients on realistic expectations of visual rehabilitation. However, these studies report different prognostic factors, as shown in Table 1.

The data are cumbersome to sort through and difficult to apply to an individual patient's case. In this study, we assessed the factors that can be determined at presentation. We examined how ocular trauma score (OTS), preoperative best-corrected visual acuity (pre-op BCVA), and zone of injury (ZOI) affect both visual acuity (VA) and surgical rehabilitation outcomes. Furthermore, we evaluated the effect of delay in wound repair on visual outcome. Finally, we assessed the effect of these risk factors on the rate of enucleation.
Correspondence: Rita D Page

Department of Ophthalmology, University of Virginia, PO Box 8007I5,

Charlottesville, VA 22908, USA

$\mathrm{Tel}+\mathrm{I} 434982$ I692

$\mathrm{Fax}+\mathrm{I} 4349245180$

Email rld9p@hscmail.mcc.virginia.edu $\mathrm{Bc}$
hererby for commercial use of this work, please see paragraphs 4.2 and 5 of our Terms (hntps://wwww.dovepress.com/terms.php). 
Table I A summary of risk factors determined to be associated with outcomes in the earlier OGI studies

\begin{tabular}{|c|c|c|}
\hline References & Outcome assessed & Risk factors associated with outcome \\
\hline Agrawal et $\mathrm{al}^{4}$ & VA & $\begin{array}{l}\text { APD, pre-op VA, blunt trauma, extent of trauma, traumatic } \\
\text { cataract, hyphema, vitreous loss, vitreoretinal trauma, zone III injury }\end{array}$ \\
\hline Agrawal et $\mathrm{al}^{5}$ & VA & APD, zone III injury, vitreoretinal trauma \\
\hline Al-Mezaine et $\mathrm{al}^{6}$ & VA, RD, hypotony & $\begin{array}{l}\text { Age, initial VA, mechanism of injury, location and extent of damage, } \\
\text { endophthalmitis }\end{array}$ \\
\hline Andreoli and Andreoli ${ }^{7}$ & Follow-up surgery, VA & $\begin{array}{l}\text { OTS, pre-repair VA, retinal hemorrhage, vitrectomy, lensectomy, } \\
\text { multiple surgeries, APD, age, scleral laceration, RD }\end{array}$ \\
\hline Emami-Naeini et al ${ }^{8}$ & VA & Fall-related mechanism, zone III injury, NLP \\
\hline Feng et $\mathrm{al}^{9}$ & NLP & Ciliary body damage, RD, choroidal damage \\
\hline Feng et $\mathrm{al}^{10}$ & NLP & $\begin{array}{l}\text { Rupture, scleral wound }>10 \mathrm{~mm} \text {, ciliary body damage, severe } \\
\text { intraocular hemorrhage, closed funnel retinal detachment or retinal } \\
\text { prolapse, choroidal damage }\end{array}$ \\
\hline Kuhn et al" & Blindness (VA worse than $20 / 200$ ) & $\begin{array}{l}\text { Age, location of injury, mechanism of injury, OS, type of injury, } \\
\text { involvement of posterior segment }\end{array}$ \\
\hline Kuhn et al ${ }^{12}$ & VA & OTS \\
\hline Yu Wai Man and Steel ${ }^{13}$ & VA & APD, initial VA, lid laceration, posterior wound, globe rupture, OTS \\
\hline Rao et $\mathrm{al}^{14}$ & VA & $\begin{array}{l}\text { Initial VA, hyphema, zone and length of injury, RD, vitreous } \\
\text { hemorrhage }\end{array}$ \\
\hline Savar et $\mathrm{al}^{15}$ & Enucleation & Rupture \\
\hline Soni et al ${ }^{16}$ & VA & Recovery of some vision on PODI, PPV, zone II injury \\
\hline Yalcin Tök et al ${ }^{17}$ & VA & Initial VA, vitreous prolapse, RD \\
\hline Knyazer et al ${ }^{18}$ & Vision retained $(\geq C F)$ or poor-no vision $(\leq \mathrm{HM})$ & $\begin{array}{l}\text { Presenting acuity, eyelid injury, iris deformity, lens damage, ocular } \\
\text { hypotonia, coexisting injuries, low OTS }(<2)\end{array}$ \\
\hline Agrawal et al ${ }^{19}$ & VA & TL between the injury and surgery, pre-op VA, mode of injury \\
\hline
\end{tabular}

Abbreviations: APD, afferent pupillary defect; CF, counting fingers; HM, hand motion; NLP, no light perception; OGI, open-globe injury; OTS, ocular trauma score; OS, left eye; pre-op, preoperative; PODI, postoperative day I; PPV, pars plana vitrectomy; RD, retinal detachment; VA, visual acuity; TL, time lapse.

\section{Patients and methods}

A retrospective chart review was conducted on 103 consecutive eyes that had been surgically treated for OGI from 2007 to 2010 at the eye clinic of the University of Virginia (UVA) in Charlottesville, VA, USA. The study was approved by the Institutional Review Board of the University of Virginia (HSR\#17326). This protocol was granted a waiver of patient consent under 45CFR46.116. Demographic and clinical data from the initial examination, primary repair, office visits, and additional surgeries were recorded in a database. The demographic and clinical data included the following: age, sex, time of injury, mechanism of injury, initial examination, open-globe repair surgical findings, follow-up examinations, surgical procedures, and outcomes. When data were missing in a particular category, the patient was excluded from the analysis. The records of 103 patients who were admitted with OGI between 2007 and 2010 were reviewed, and 64 patients were included in the analysis. A total of 39 patients with $<6$ months of follow-up, incomplete medical records, or a history of previous ocular injury to the same eye were excluded from the study.

\section{Risk factors assessed}

Four risk factors (pre-op BCVA, OTS, ZOI, and time lapse $[\mathrm{TL}]$ between injury and primary repair) were identified for investigation.
There were 22 distinct preoperative and final Snellen VAs that were recorded. These VAs were ranked in order of severity, and then a number 1-22 was assigned to each VA for statistical analysis. The VA ranking system is detailed in Table 2.

When possible, OTS was calculated based on the information recorded from the examination at presentation and the primary surgery, as described by Kuhn et al, ${ }^{12}$ where OTSs in category 1 were the most severely injured eyes and category 5 were the least injured. The method of calculating OTS is summarized in Table 3.

Table 2 VA rank for statistical analysis

\begin{tabular}{llll}
\hline Rank & Snellen & Rank & Snellen \\
\hline 1 & $20 / 20$ & 12 & $20 / 300$ \\
2 & $20 / 25$ & 13 & $20 / 400$ \\
3 & $20 / 30$ & 14 & $6 / 200$ \\
4 & $20 / 40$ & 15 & $5 / 200$ \\
5 & $20 / 50$ & 16 & $4 / 200$ \\
6 & $20 / 60$ & 17 & $3 / 200$ \\
7 & $20 / 70$ & 18 & $\mathrm{CF}(2 / 200)$ \\
8 & $20 / 80$ & 19 & $\mathrm{I} / 200$ \\
9 & $20 / 100$ & 20 & $\mathrm{HM}$ \\
10 & $20 / 150$ & 21 & $\mathrm{LP}$ \\
$\mathrm{II}$ & $20 / 200$ & 22 & $\mathrm{NLP}$ \\
\hline
\end{tabular}

Abbreviations: CF, counting fingers; HM, hand motion; LP, light perception; NLP, no light perception; VA, visual acuity. 
Table 3 Method for calculating OTS

\begin{tabular}{ll}
\hline Calculating the OTS raw points & \\
\hline Variable & Raw points \\
Initial vision & 60 \\
NLP & 70 \\
LP/HM & 80 \\
I/200-19/200 & 90 \\
$20 / 200-20 / 50$ & 100 \\
$\geq 20 / 40$ & -23 \\
Rupture & -17 \\
Endophthalmitis & -14 \\
Perforating injury & -11 \\
Retinal detachment & -10 \\
Afferent pupillary defect & \\
\hline Conversion of raw points into OTS category & OTS \\
\hline Sum of raw points & 1 \\
$0-44$ & 2 \\
$45-65$ & 3 \\
$66-80$ & 4 \\
8 I-9I & 5 \\
$92-100$ &
\end{tabular}

Abbreviations: LP, light perception; HM, hand motion; NLP, no light perception; OTS, ocular trauma score.

ZOI was determined from the data recorded during the primary surgery according to "A System for Classifying Mechanical Injuries of the Eye". ${ }^{20}$ Zone I was recorded for breaks in the globe limited to the cornea. Zone II injuries involved the anterior section of the sclera, that is within $5 \mathrm{~mm}$ of the corneoscleral limbus. Zone III injuries also involved the sclera, but extended $>5 \mathrm{~mm}$ posterior to the corneoscleral limbus. When there was no precise record of how posteriorly a scleral wound extended, "zone II or III" was elected.

TL was calculated using the time and dates recorded for the OGI and primary repair on the emergency department note and the surgical note, respectively.

\section{Outcomes assessed}

Three outcomes (final BCVA, monthly rate of additional surgeries [MRAS], and enucleation) were identified for the analysis. Final BCVA was determined from the last follow-up examination of the eye at the time of chart review in August 2014. MRAS was calculated by dividing the total number of ocular surgeries the patient underwent for the OGI by the number of months of follow-up.

Data were analyzed via univariate and multivariate Spearman's rank correlations and univariate and multivariate logistic regression.

\section{Results}

The patient population included in the study was mostly male (78.1\%). The mean age was $41.8 \pm 22$ years (range: $3-88$ years).
The types of injuries from most to least common were laceration $(27 / 64 ; 42.2 \%)$, rupture $(23 / 64 ; 35.9 \%)$, penetrating injury $(10 / 64 ; 15.6 \%)$, perforating injury $(3 / 64 ; 4.7 \%)$, and intraocular foreign body $(1 / 64 ; 1.6 \%)$. The most common mechanisms of injury were: fall $(11 / 64 ; 17 \%)$, metal nail $(11 / 64 ; 17 \%)$, projectile $(10 / 64 ; 16 \%)$, assault $(7 / 64 ; 11 \%)$, motor vehicle collision $(6 / 64 ; 9 \%), \mathrm{BB} /$ pellet gun $(6 / 64$; $9 \%)$, blade $(5 / 64 ; 8 \%), \operatorname{wood}(4 / 64 ; 6 \%)$, blunt impact $(2 / 64$; $3 \%)$, glass $(1 / 64 ; 2 \%)$, and opening of surgical wound ( $1 / 64$; $2 \%)$.

The majority of the patients sustained severe ocular injury with OTSs of $1(27.8 \%)$ or $2(35.2 \%)$. Approximately onethird of the patients had an OTS of $3(22.2 \%)$ or $4(13.0 \%)$. Only one patient $(1.9 \%)$ had an OTS of 5 . Furthermore, prerepair VA was hand motion or worse for more than two-thirds of the patients. The injuries were split almost evenly between zone I ( $46.9 \%)$ and zone II or III (53.1\%).

The median TL between injury and primary repair was 8.9 hours (range: $2.7-111.4$ hours). A total of six patients (12\%) underwent primary repair $>1$ day after their OGI occurred. The average duration of the primary repair was 2.4 hours (range: $0.3-7.3$ hours).

The average number of surgeries per patient, including the initial open-globe repair, was 2.5 (range: 1-7). A majority of the patients (75\%) required an additional surgery after primary repair. Seven patients (10.3\%) ultimately underwent enucleation. The median follow-up time was 19.3 months (range: 6.1-89.8 months). There were a total of 1,314 follow-up visits, averaging 20.5 per patient.

There were a total of six patients in this study who presented with NLP presurgical repair vision and who had at least 6 months of follow-up and a final BCVA recorded. All of these patients underwent primary repair in an attempt to salvage the eye. Three out of the six patients (50\%) eventually underwent enucleation. One patient had five total surgeries before the eye was enucleated. One-third of these patients regained some sight (one to hand motion and one to light perception), as shown in Table 4.

Table 4 Outcomes for patients who presented with no light perception VA

\begin{tabular}{llll}
\hline Patient & Final VA & Total number of surgeries & Enucleation \\
\hline 1 & HM & 3 & No \\
2 & LP & 2 & No \\
3 & NLP & 1 & No \\
4 & NLP & 5 & Yes \\
5 & NLP & 3 & Yes \\
6 & NLP & 2 & Yes \\
\hline
\end{tabular}

Abbreviations: HM, hand motion; LP, light perception; NLP, no light perception; VA, visual acuity. 
Table 5 Age-adjusted associations between preoperative risk factors and postoperative outcomes

\begin{tabular}{|c|c|c|c|}
\hline \multirow[t]{2}{*}{ Predictor variable } & \multicolumn{3}{|l|}{ Outcome variable } \\
\hline & MRAS & BCVA final rank & Enucleation \\
\hline Pre-op BCVA rank & $P=0.00 I$ ( + association) & $P<0.00$ I (+ association) & $P=0.039(+$ association $)$ \\
\hline Calculated OTS & $P=0.024$ ( - association) & $P<000$ I ( - association) & $P=0.04 I$ ( - association $)$ \\
\hline Zone I injury & $P=0.452$ (no association) & $P=0.417$ (no association) & $P=0.569$ (no association) \\
\hline TL: injury to surgery (hours) & $P=0.867$ (no association) & $P=0.6 \mathrm{I}$ (no association) & $P=0.517$ (no association) \\
\hline
\end{tabular}

Note: The associations between predictor and outcome variables that were statistically significant are highlighted in bold.

Abbreviations: BCVA, best-corrected visual acuity; MRAS, monthly rate of additional surgeries; OTS, ocular trauma score; pre-op, preoperative; TL, time lapse.

Pre-op BCVA was positively associated with MRAS, final BCVA, and enucleation. Calculated OTS was negatively associated with the outcome variables. No association was found between the predictor variables TL and ZOI with the outcome variables. Age-adjusted associations between preoperative risk factors and postoperative outcomes are summarized in Table 5.

Further, age and predictor variable-adjusted analyses showed pre-op BCVA to be independently positively associated with MRAS $(P=0.008)$ and with final BCVA $(P<0.001)$. However, calculated OTS was independently negatively associated with final BCVA $(P<0.001)$, but not uniquely associated with MRAS $(P=0.530)$.

\section{Discussion}

The aftermath of an OGI can be arduous. In this study, patients sustained up to seven total surgeries on the eye, up to 87 follow-up appointments in 3-4 years post-injury, and the overall VA outcome for the eye was often still poor. One out of ten patients eventually developed a blind, painful eye and required enucleation. It is vital for the physician to be able to look at certain indicators prior to or during the primary repair that will provide accurate information about the likelihood of visual recovery. In this study, we evaluated how pre-op BCVA, OTS, ZOI, and TL between injury and repair predicted outcomes for patients who sustained OGI, specifically final BCVA, additional surgeries, and enucleation.

Many studies have determined that poor presurgical repair VA predicts poor final VA for patients with OGI., 4,6,7,13,14,17 This study also showed that patients with poor pre-op BCVA were more likely to have a poor final VA, to require more additional surgeries, and to undergo enucleation. Under multivariate analysis, this factor was independently associated with visual and surgical prognosis.

However, the accurate determination of VA in an eye injury case in the emergency department is quite challenging; in some cases, the patient may not be fully cooperative, even if he/she is neurologically stable. Furthermore, the distorted anatomy of the globe, periocular structures, and the orbit may mislead even an experienced examiner; periocular hemorrhages and edema in addition to profuse tearing also add to the difficulty.

Often in ophthalmologic studies, the logarithm of the minimum angle of resolution (logMAR) equivalent of the snellen chart is utilized for analysis of visual acuities. This is because the logMAR scale is continuous, allowing for easier calculations. Since there is no logMAR equivalent for NLP, we ranked the VAs from best to worst in order to analyze the data. Other studies on ocular trauma have ranked VAs as well. In their study on preoperative variables that affect final vision outcome for zone III injuries, Agrawal et al ${ }^{4}$ divided VA into five groups. Ranking the VAs instead of using a continuous scale such as logMAR limits our ability to analyze VA outcomes accurately.

OTS was defined by Kuhn et al ${ }^{12}$ in order to simplify the process of predicting visual prognosis for patients with OGI. It uses variables at presentation, such as presenting VA, type of injury, and the presence of retinal detachment, endophthalmitis, and afferent pupillary defect to determine the likelihood of different final VAs. This study revealed that calculated OTS was associated with VA prognosis. The lower the OTS, the more severe the injury was, and the worse the visual outcome became. This study adds to the evidence in the literature that the OTS predicts VA outcome. ${ }^{7,12,13,18}$ In some studies, zone III injuries, defined as extending $>5 \mathrm{~mm}$ posterior to the corneoscleral limbus, have been shown to have statistically poorer prognosis than other OGIs due to their extent past the pars plana into the posterior segment of the eye where structures such as the retina and choroid are more likely to be damaged. ${ }^{4,5,8}$ In our cohort, no association was found between ZOI and the outcome variables. However, this could be due to this study's inability to distinguish OGIs with true posterior involvement. Zones II and III were grouped for analysis because a minority of surgical records did not state the scleral extension of the wound.

There was no difference in outcome based on TL between injury and primary repair in our series. The range of time to surgery in this study was $2.7-111.4$ hours (interquartile 
range: $7.4-17.8$ hours), and $88 \%$ of our cohort underwent repair within 1 day of their OGI. Therefore, it is possible that the range of our data was not great enough to detect a difference in outcomes between patients who underwent primary repair, early or delayed. In a larger study of 669 patients with OGI in India, TL between the injury and surgery was found to adversely impact the visual outcome. ${ }^{20}$ Since other studies have reported that a delay in primary wound closure is a risk factor for endophthalmitis ${ }^{21}$ and sympathetic ophthalmia, ${ }^{22}$ prompt surgical repair is still recommended. Our finding, however, offers hope to cases where a patient presents late after an ocular injury. While these patients' risk for rare complications is increased, their overall VA in the absence of infection or sympathetic ophthalmia may remain unchanged.

We chose to limit the chart review for this study from 2007 until 2010 for multiple reasons. At this institution, 2007 was the first year that charts were consistently available in the electronic medical record. Analyzing patients with injuries up until December 31, 2010, allowed for substantial follow-up time. Because this study only spanned 4 years, our patient population size was limited. The retrospective nature of this study further limits the interpretation of our results as the calculation of OTS and interpretation of ZOI were not performed when the patient presented with the OGI. Instead, they were retrospectively obtained from the emergency department and primary surgical repair notes.

The physical and psychological impact following a severe eye injury is difficult to quantify. It is generally accepted today that primary surgical closure of an open globe should be undertaken no matter how extensive the injury is and how doubtful the visual recovery may be, because of the assumption that any patient who enters the operating room with a traumatized eye anticipates recovery. For example, Savar et $\mathrm{al}^{15}$ have concluded that it is reasonable to follow patients with NLP after OGI instead of attempting primary enucleation and advocate for attempted primary repair whenever possible, citing the psychological consequences to enucleation and the relatively low risk of sympathetic ophthalmia ( $0.3 \%$ in their series of 660 OGIs). Alternatively, the psychological impact of losing an eye after multiple clinic visits and additional surgeries may be quite traumatic as well. In addition, in the setting of today's cost-conscious medical practice, the price of undergoing multiple surgeries and clinic visits before eventual loss of the eye should be taken into account. More research and discussion on this topic are warranted.

Like many other previous reports, this study reveals that conventional clinical features are not reliable enough to decide on the primary enucleation of massively damaged globes at the time of initial admission. In the future, it is possible that imaging modalities such as magnetic resonance imaging (MRI) may provide impartial findings that the traumatized eye is left without any visual potential. New MRI methodologies, principally the advanced applications of functional MRI (fMRI), open new possibilities for this technology to be utilized in clinical ophthalmology. For example, proton MRI can be used noninvasively to generate a T1-weighted image of the eye in both hyperoxic and hypercapnic inhalation challenge to measure the inner retinal oxygen response. ${ }^{23}$ This response is likely to be abnormal if the retina is poorly perfused because of retinal pathology. fMRI has been used to study pathologies such as retinal degeneration, diabetic retinopathy, and glaucoma in rodent models. ${ }^{24,25}$ Furthermore, it has proven to be feasible to study human retinas with blood-oxygenation-level-dependent MRI and blood flow MRI. ${ }^{26}$ This imaging modality has never been used for OGIs, and there are many challenges currently for its general use, including cost. However, with advances in fMRI methodology in the future, this technology may allow for more reliable prediction of prognosis in eyes with OGI than is currently possible today.

\section{Conclusion}

In OGI, a poor pre-op BCVA is associated with poorer VA outcomes, more additional surgeries, and a higher rate of enucleation. A lower OTS signifies a more significant injury and is predictive of a worse VA outcome. ZOI and TL between injury and repairs are not predictive of outcomes. Like other reports, however, this study revealed that conventional clinical features are not reliable enough to determine the course of treatment assuredly, particularly to decide on the primary enucleation of massively damaged globes at the time of initial admission. A more objective judgment of this sort may come from advanced applications of fMRI, which are promising to open new avenues in clinical ophthalmology.

\section{Disclosure}

The authors report no conflicts of interest in this work.

\section{References}

1. Kuhn F, Morris R, Witherspoon CD. Birmingham Eye Trauma Terminology (BETT): terminology and classification of mechanical eye injuries. Ophthalmol Clin North Am. 2002;15(2):139-143.

2. Morris R, Kuhn F, Witherspoon CD, Stephens DDC. Counseling the patient and the family. In: Kuhn F, Pieramici D, editors. Ocular Trauma: Principles and Practice. New York: Thieme; 2002:22-26.

3. Parver LM. Eye trauma. The neglected disorder. Arch Ophthalmol. 1986;104(10):1452-1453. 
4. Agrawal R, Wei HS, Teoh S. Pre-operative variables affecting final visual outcome with a critical review of ocular trauma classification for posterior open globe (zone III) injury. Indian J Ophthalmol. 2013;61(10): 541-545.

5. Agrawal R, Wei HS, Teoh S. Predictive factors for final outcome of severely traumatized eyes with no light perception. BMC Ophthalmol. 2012;12:16.

6. Al-Mezaine HS, Osman EA, Kangave D, Abu El-Asrar AM. Prognostic factors after repair of open globe injuries. J Trauma. 2010;69(4): 943-947.

7. Andreoli MT, Andreoli CM. Surgical rehabilitation of the open globe injury patient. Am J Ophthalmol. 2012;153(5):856-860.

8. Emami-Naeini P, Ragam A, Bauza AM, et al. Characteristics, outcomes, and prognostic indicators of fall-related open globe injuries. Retina. 2013;33(10):2075-2079.

9. Feng K, Shen L, Pang X, et al. Case-control study of risk factors for no light perception after open-globe injury: eye injury vitrectomy study. Retina. 2011;31(10):1988-1996.

10. Feng K, Hu YT, Ma Z. Prognostic indicators for no light perception after open-globe injury: eye injury vitrectomy study. Am J Ophthalmol. 2011;152(4):654-662.

11. Kuhn F, Morris R, Witherspoon CD, Mann L. Epidemiology of blinding trauma in the United States eye injury registry. Ophthalmic Epidemiol. 2006;13(3):209-216.

12. Kuhn F, Maisiak R, Mann L, Mester V, Morris R, Witherspoon CD. The ocular trauma score (OTS). Ophthalmol Clin North Am. 2002;15(2): 163-165.

13. Yu Wai Man C, Steel D. Visual outcome after open globe injury: a comparison of two prognostic models - the ocular trauma score and the classification and regression tree. Eye (Lond). 2010;24(1):84-89.

14. Rao LG, Ninan A, Rao KA. Descriptive study on ocular survival, visual outcome and prognostic factors in open globe injuries. Indian J Ophthalmol. 2010;58(4):321-323.

15. Savar A, Andreoli MT, Kloek CE, Andreoli CM. Enucleation for open globe injury. Am J Ophthalmol. 2009;147(4):595-600.
16. Soni NG, Bauza AM, Son JH, Langer PD, Zarbin MA, Bhagat N. Open globe ocular trauma: functional outcome of eyes with no light perception at initial presentation. Retina. 2013;33(2):380-386.

17. Yalcin Tök O, Tok L, Eraslan E, Ozkaya D, Ornek F, Bardak Y. Prognostic factors influencing final visual acuity in open globe injuries. J Trauma. 2011;71(6):1794-1800.

18. Knyazer B, Levy J, Rosen S, Belfair N, Klemperer I, Lifshitz T. Prognostic factors in posterior open globe injuries (zone-III injuries). Clin Experiment Ophthalmol. 2008;36(9):836-841.

19. Agrawal R, Rao G, Naigaonkar R, Ou X, Desai S. Prognostic factors for vision outcome after surgical repair of open globe injuries. Indian J Ophthalmol. 2011;59(6):465-470.

20. Pieramici DJ, Sternberg P Jr, Aaberg TM Sr, et al. A system for classifying mechanical injuries of the eye (globe). The Ocular Trauma Classification Group. Am J Ophthalmol. 1997;123(6):820-831.

21. Ahmed Y, Schimel AM, Pathengay A, Colyer MH, Flynn HW Jr. Endophthalmitis following open-globe injuries. Eye (Lond). 2012;26(2): 212-217.

22. Şen HN, Nussenblatt RB. Sympathetic ophthalmia: what have we learned? Am J Ophthalmol. 2009;148(5):632-633.

23. Cheng H, Nair G, Walker TA, et al. Structural and functional MRI reveals multiple retinal layers. Proc Natl Acad Sci US A. 2006;103(46): $17525-17530$

24. Nair G, Pardue MT, Kim M, Duong TQ. Manganese-enhanced MRI reveals multiple cellular and vascular layers in normal and degenerated retinas. J Magn Reson Imaging. 2011;34(6):1422-1429.

25. Zhang Y, Nateras OS, Peng Q, et al. Lamina-specific anatomic magnetic resonance imaging of the human retina. Invest Ophthalmol Vis Sci. 2011; 52(10):7232-7237.

26. Zhang Y, Peng Q, Kiel JW, Rosende CA, Duong TQ. Magnetic resonance imaging of vascular oxygenation changes during hyperoxia and carbogen challenges in the human retina. Invest Ophthalmol Vis Sci. 2011;52(1):286-291.
Clinical Ophthalmology

\section{Publish your work in this journal}

Clinical Ophthalmology is an international, peer-reviewed journal covering all subspecialties within ophthalmology. Key topics include: Optometry; Visual science; Pharmacology and drug therapy in eye diseases; Basic Sciences; Primary and Secondary eye care; Patient Safety and Quality of Care Improvements. This journal is indexed on

\section{Dovepress}

PubMed Central and CAS, and is the official journal of The Society of Clinical Ophthalmology (SCO). The manuscript management system is completely online and includes a very quick and fair peer-review system, which is all easy to use. Visit http://www.dovepress.com/ testimonials.php to read real quotes from published authors. 